\title{
Organizational Ambidexterity: How Small Technology Firms Balance Innovation and Support
} John Schreuders and Alem Legesse

\author{
"The pessimist complains about the wind. The optimist") \\ expects it to change. The leader adjusts the sails. \\ John Maxwell \\ Author and Speaker
}

\begin{abstract}
Many technology entrepreneurs start their companies by focusing on an innovation that creates a market offer to attract their first customers. When the entrepreneur's firm makes its first sale, the dynamics of the organization change and the entrepreneur faces a new challenge: how can the firm concurrently develop new products and support existing customers? This problem is of great concern to entrepreneurs who own small technology firms and is the subject of this article.
\end{abstract}

In this article, we first address the innovate-versus-support dilemma that small technology firms face early in their lifecycles. Next, we describe the paradigm of the ambidextrous organization. We conclude with a discussion of five mechanisms small firms can use to achieve balance in their quest to concurrently satisfy the need to innovate while fulfilling the demands of existing clients and products.

\section{Introduction}

Early in a technology firm's lifecycle, most of the firm's time and resources are dedicated to the design and development of its first product. This is known as the "honeymoon" stage for a startup. The entrepreneur can afford to be extremely flexible with goals and decisions. Once the firm begins to ship products and establishes a group of customers, it must devote a portion of its resources to the maintenance of those products through regular bug fixes and product updates (i.e., customer support). This shift in priorities places a firm in an interesting dilemma: existing customers must be kept satisfied while pressures to continue innovation must be addressed.

To survive and grow, the small technology firm needs to find a balance between satisfying existing customers and developing new products. If the entrepreneur fails to properly balance the need for new product development and the need to keep existing customers satisfied, then one of the following two outcomes may happen. First, the small technology firm may no longer be able to innovate at the pace required to stay ahead of the larger incumbents, resulting in the firm becoming irrelevant and ripe for replacement by an incumbent. Second, the small firm may develop a poor reputation, resulting in unhappy customers who go elsewhere.

The search for the appropriate balance is at the heart of a research paradigm known as organizational ambidexterity (Raisch et al., 2009; tinyurl.com/84jzpbn). An ambidextrous organization is one that is capable of simultaneously exploiting existing competencies (e.g., satisfying existing customers) and exploring new opportunities (e.g., developing new products). However, exploration and exploitation are quite different activities and require different abilities within the firm. In the case of exploration, "firms must regularly assess their vision, encourage innovation and must be willing to adjust or change strategies, products and markets and more" (Dover and Dierk, 2010; tinyurl.com/7pcll3j). Ex- 


\section{Organizational Ambidexterity: How Firms Balance Innovation and Support} John Schreuders and Alem Legesse

ploitation requires a different approach; the firm must focus on carrying out activities such as customer service and bug fixes as efficiently as possible. Exploration employs more of a creative, dynamic approach necessary for innovating new products faster than the competition. This is much different than exploitation, which employs a transactional approach with a focus on ensuring customer satisfaction.

Ambidextrous organizations are expected to perform better than others (Raisch et al., 2009; tinyurl.com/84jzpbn), but the existing literature focuses on the mechanisms required to enable ambidexterity and addresses the importance of the relationship between ambidexterity and firm performance in mid- and large-scale organizations. The literature regarding ambidexterity within small technology firms is not well developed. Entrepreneurs who own small technology firms should be aware that the balance between exploration and exploitation is of crucial importance to the success of their firms (Rosing et al., 2011; tinyurl.com/72eyvmv). They must also be familiar with the mechanisms that can help a small technology company become more ambidextrous.

The remainder of this article describes five mechanisms that entrepreneurs can use to design and operate ambidextrous small technology firms:

1. Adopt an ambidextrous leadership style.

2. Outsource one of the two functions.

3. Attract and retain employees who can both explore and exploit.

4. Attract executives who can act as leaders, managers, and entrepreneurs.

5. Shift resources across projects regardless of whether their goals are to explore or exploit.

\section{Adopt an ambidextrous leadership style}

Leadership affects innovation and organizational development. Rosing, Frese, and Bausch (2011; tinyurl.com/ 72eyvmv) identify three leadership styles found within a technology company: transformational, transactional, and ambidextrous. These leadership styles are described below to illustrate their roles at different phases in the lifecycles of companies.

A transformational leader strives to make changes within the organization for the purpose of moulding it into something different. This is done to prepare the organization for challenges, such as handling new technologies or new incumbents. This style of leadership tends to result in unconventional thinking and solutions that go beyond existing knowledge. For the entrepreneur starting a technology business, this leadership style generally works best. Typically, an entrepreneur starts with an idea, then transforms it into an opportunity, and then it becomes a small operating business. Later, the entrepreneur is faced with the dilemma of having to shift their leadership style as the firm evolves.

A transactional leader focuses on maintaining day-today operations, assuring the firm runs as efficiently as possible. This leadership style tends to focus on correcting issues that impact the effectiveness of the firm's day-to-day operations. It is less concerned with transforming the organization to handle future changes in the market. The transactional leadership style is most evident in large firms with well established brands. These firms invest mainly in initiatives to promote their brands and ensure their existing customer base is satisfied. When an organization focuses exclusively on transactional leadership, however, it finds it difficult to develop novel new products and services. This leaves the larger firm vulnerable to smaller, less well-known firms that are free to devote their time to innovation (Rosing et al., 2011; tinyurl.com/72eyvmv). The reverse seems true for small companies that have fewer customers and are focused primarily on product development. Once their product development begins to pay off, the small company must integrate transactional leadership into the organization to provide support for their growing customer base.

Ambidextrous leadership is a combination of both the transformational and transactional leadership styles. Ambidextrous leaders have mastered the ability to alternate between the two styles depending on the needs of the company. Ambidextrous leadership successfully establishes the right balance in order to promote growth within the company. Leaders of startups must be able to efficiently change from one leadership style to the next depending upon the innovation requirements. Simply keeping up with both styles does not lead to higher innovation (Rosing et al., 2011).

An example of ambidextrous leadership comes from International Safety Research Incorporated (i-s-r.ca), which is a small firm committed to providing safety management solutions in the fields of nuclear power and radiation protection. The company consists of a small collection of licensed safety inspectors and software de- 


\title{
Organizational Ambidexterity: How Firms Balance Innovation and Support
}

\author{
John Schreuders and Alem Legesse
}

velopers who can switch efficiently between re-certification tasks for existing customers and new product development related to their exercise simulation product (i-s-r.ca/products_e.html) or other innovations. To effectively balance the nature of these responsibilities, the staff must continuously shift from customer support to new product development. The ability to alternate between explorative and exploitative work benefits International Safety Research Incorporated; it creates an efficient system where lessons learned from customer support can be incorporated into the improvement of upcoming products. Due to the size of ISR, leaders within the company must shift their focus from customer service to product development along with the rest of the staff. In fact, it is due to the ambidextrous nature of its leadership that ISR employees can themselves be ambidextrous.

\section{Outsource one of the two functions}

A small company that wishes to strike a balance between supporting customers and developing innovating new products can enter into partnerships with other companies to perform one of these two functions. When engaging a partner to perform one of the two functions, and for externalization to work properly, the small firm must maintain strong ties with the partner and integrate the externally acquired knowledge base back into the organization (Raisch et al., 2009; tinyurl.com/84jzpbn).

An example is Blindside Networks (blindsidenetworks.com), a Carleton University spin-off company that produces open source web conferencing solutions for universities and colleges. Blindside generates revenue supporting existing customers (exploitation) and innovates by collaborating with the global BigBlueButton (bigbluebutton.org) open source community (exploration) (Dixon, 2011; timreview.ca/article/441). It was the strategic decision to outsource exploration activity that allowed the startup to develop a complex web application and quickly deploy it to customers. Another example is InGenius (ingenius.com), which provides telecommunication software solutions. InGenius entered into an agreement with Mitel Networks (www.mitel.ca) to develop components for Mitel's MCD platform. In turn, Mitel assumes the responsibility of handling customer support tasks. Through this arrangement, InGenius can focus aggressively on new product development while its partner can focus on providing a unified customer support experience. In this situation, a small company has partnered with a larger one to create an ambidextrous collaboration for mutual advantage.

\section{Attract and retain employees who can both explore and exploit}

Researchers have focused on firm-level mechanisms to enable ambidexterity. Many employees of smaller firms, however, are forced to take on both exploitative and explorative tasks. Individual-level mechanisms that enable ambidexterity assume that ambidextrous capability is rooted in the individual or small team, not the overall organization. In the case of a small company, resources may not be available to hire people specifically for the development and support functions. Ideally, these employees should learn to perform tasks that support both functions. A single team may become ambidextrous by allocating different roles to each individual (Raisch et al., 2009; tinyurl.com/84jzpbn).

Consider Met Inspiratie (metinspiratie.nl), a small web design firm operating in the Netherlands. The firm consistently secures customer contracts because their design team develops innovative products and provides customer support. Due to its size, designers at Met Inspiratie take care of clients through the whole lifecycle of product design from inception to final deployment. This gives customers the "personal touch" they do not receive from larger firms. This ambidexterity gives designers more direct access to their customers and allows them to develop the relationships that enable them to anticipate their customers' needs. By having these strong relationships cemented early in the design phase of a project, designers can ensure all requirements are incorporated into the final design and the customer's needs are always considered. Another example is the Zope Europe Association (ZEA; zeapartners.org), which is a network of small firms of one or more employees that collaborate to operate as an ambidextrous organization (Weiss, 2011; http://www.timreview.ca/article/436). The network enables its members to partition tasks so they can innovate as well as provide customer support. These examples illustrate that it is important to attract employees who possess the skills and breath of prior knowledge and understanding necessary to perform both exploitation and exploration tasks (Raisch et al. 2009; tinyurl.com/84jzpbn).

\section{Attract executives with balanced capabilities}

Executives who can view a firm's problems from the perspective of a leader, a manager, and an entrepreneur add to the firm's ambidextrous capability. Dover and Dierk (2010; tinyurl.com/7pcll3j) defined an index whereby executives can be ranked in terms of their effectiveness on three separate scales: manager, entrepreneur, and leader. Executives with high scores in the 


\title{
Organizational Ambidexterity: How Firms Balance Innovation and Support
}

\author{
John Schreuders and Alem Legesse
}

manager dimension are driven by short-term objectives and clear metrics, and they tend to be risk averse. Executives with high scores as entrepreneurs are risk takers. Executives with high scores in the leadership dimension take a middle course; through vision and future orientation, they show a propensity for risk, while at the same time, they carefully search for a balanced portfolio of innovation opportunities.

The ability to balance managerial, entrepreneurial, and leadership effectiveness optimizes a firm's capability to incorporate customer inputs generated by support activities into product development. Achieving this balance also encourages the entrepreneur to assume more risk based on their knowledge of what customers need, because they are strongly linked to the market. Executives who can effectively integrate exploitative and explorative activities have the ability and power to transform a small company into an ambidextrous one (Raisch et al., 2009; tinyurl.com/84jzpbn). This will allow the small company to better handle contradictions and conflicting goals (Smith and Tushman, 2005; tinyurl.com/8xcd9bn), engage in paradoxical thinking, and fulfil multiple roles (Raisch et al., 2009).

\section{Shift resources across projects}

Some researchers suggest that ambidexterity can be obtained by shifting resources from one project to the next, regardless of whether the project goals are explorative or exploitative in nature. These resources can include: cash, talent, expertise, customers, and technologies (O'Reilly and Tushman, 2004; tinyurl.com/6uavbe6). In its ability to effectively shift resources from one project to the next, the small technology firm benefits in the following ways:

1. Increased customer satisfaction during periods of increased demand for support

2. Reduced time required to allocate resources to take advantage of a new market opportunity and remove resources used to support products in declining markets

3. Increased ability to respond to environmental changes such as the arrival of a new incumbent or new technology

A technology startup that can easily move resources from development to customer support improves its ability to compete. The firm can innovate effectively since those who are familiar with the designs of the product are also familiar with the needs, complaints, and expectations of customers. This customer-driven knowledge can potentially translate into better requirements, more comprehensive testing, and simpler customer deployment.

The ability for a startup to quickly shift from development to support and back again is crucial to responding to environmental changes. Consider the company thinkRF (thinkrf.com), a small firm specializing in the development of software-enabled radio frequency analysis tools. The company consists of less than a dozen hardware and software engineers who perform both development and customer support tasks. To help with its growth, thinkRF has partnered with the large investment firm Wesley Clover (wesleyclover.com), which specializes in telecommunication companies and provides thinkRF with sales contacts and partnerships that leads directly to new business opportunities. This structuring allows thinkRF to focus on switching between customer support and product development without having to divert resources to marketing and sales. This arrangement between a small and large company allows the small company to remain lean and agile by focusing on what it does best: solving technical problems.

\section{Conclusion}

The challenges of survival and growth are a constant concern for the small business entrepreneur. Frequently, a startup must compete in a market dominated by larger companies that have more staff and resources at their disposal. The small company's advantage is that it is more agile than its competitors. If properly managed, a startup can have an advantage over its larger competitors by more efficiently providing customer support and simultaneously working on new product development

Balancing support and research activities - both simultaneously and effectively - is what the ambidextrous organization strives to accomplish. In this article, we identified five mechanisms that can be used to improve a technology company's ability to juggle support and development tasks. These mechanisms offer a useful set of guidelines an entrepreneur can consider when planning growth strategies for a market environment that demands multitasking. 


\title{
Organizational Ambidexterity: How Firms Balance Innovation and Support
}

John Schreuders and Alem Legesse

\begin{abstract}
About the Authors
John Schreuders is a senior software systems engineer at Mitel Networks in Kanata, Ontario. John is a licensed professional engineer with Professional Engineers Ontario (PEO). After graduating from the Royal Military College in Kingston, John Schreuders started his engineering career as a combat systems engineer in the Canadian Navy. After that, he went on to work for defense contractors and later for the International Space Station project. Recently John returned from working in New York as a software systems engineer for Wall Street. He is currently pursuing his Master's degree in Technology Innovation Management at Carleton University in Ottawa, Canada.
\end{abstract}

Alem Legesse is pursuing his MEng studies in Carleton University's Technology Innovation Management program in Ottawa, Canada. He is the founder of Syncrodata Inc., a software company that provides software development services for Android, Blackberry, and IOS devices. He holds an MSc degree offered jointly by computer science, engineering, and mathematics at Carleton University. His research interests are mobile developments, telecommunications, open source, and business models. He previously worked as a software designer for RIM, Alcatel-Lucent, and Nortel, and as a flight security analyst for Transport Canada. 